\title{
SYNTHESIS AND CHARACTERIZATION OF TERNARY PT-ALLOY NANO PARTICLES FOR HYDROGEN FUEL CELL APPLICATION
}

\author{
Alhassan Kabiru Usman*and Kamal Danazumi \\ Department of Chemistry, Kaduna State University, Kaduna-Nigeria \\ *Corresponding author; kabirusman86.aku@gmail.com; alhassan.usman@kasu.edu.ng
}

\begin{abstract}
A novel ternary PtM 2 nano structures was prepared using simple salvothermal process. The alloy formation has been ascertained using different characterizations techniques such as $X$-ray diffraction, Tunneling electron microscope TEM, Scanning electron microscope SEM, EDX. The XRD pattern reveals that, the peak position was shifted to higher $2 \theta$ angle specifying the presence of $\mathrm{Co}$ and $\mathrm{Ni}$ into the lattice to form an ordered $L_{10}$ phase with a reduced Pt-Pt distance. The thickness of the alloy was found to be $\sim 4.3 \mathrm{~nm}$ and interplaner distance of $\sim 0.23 \mathrm{~nm}$ which correlate with TEM analysis with an average particle size $\sim 20 \mathrm{~nm}$ and distribution of the catalyst on carbon support was also investigated by TEM images. SEM was used to obtain the surface morphology of the synthesized catalyst as well the amount of metallic loaded from EDX.

Key words; Platinum, Cobalt, Nickel on Carbon Support (PCN/C), Platinum, Cobalt and Nickel for 8 hour (PCN-8h), Commercial Platinum on Carbon Support (Pt/C), Oxidation Reduction Reaction (ORR), PEMFC, SEM, EDX, TEM, XRD.
\end{abstract}

\section{INTRODUCTION}

There are three major driving forces for the increasing interests in the development of fuel cells. One is the reality that fossil fuels are running out, the world primary energy consumption is expected to grow by more than $30 \%$ from 2013 to 2030, and several studies have indicated that the reserve for the crude oil and gas, the main fossil fuel resources for world energy supply, will near an end within the next 50 years, and we have to $f$ ind alternative energy sources (Thinnes, 2012; Shafiee, 2009). Secondly is the efficiency of fuel cell. The other is the fact that the pollution from using fossil fuels has become an important issue of environmental concern to human health. Fuel cells utilizing hydrogen as fuels represent an important form of tomorrow's energy because hydrogen is an efficient fuel and is environmentally clean. Imagine that a stack of hydrogen fuel cells can create enough current to power a vehicle, a building and even an entire city, and the only byproduct is water, which makes fuel cells the most energy-efficient and environmentally-friendly technology on the horizon. The auto industry, which relies on oilfuelled cars, is perhaps the biggest driving force behind the massive investment in fuel cell development ${ }^{3}$. This is understandable because the price of oil is extremely volatile and has been increasing in the past few years which are likely to continue upwards. Moreover, the harmful emissions of $\mathrm{CO}_{2}, \mathrm{CO}, \mathrm{SO}_{2}, \mathrm{NOx}$, and volatile organic compounds into the atmosphere cause serious environmental damage, increase respiratory problems in humans, and produce "greenhouse gas" that contributes to global warming. With these problems, fuel cell technology is inevitably seen as a viable alternative. This is now attracting tremendous interest as reliable primary power source for its higher energy conversion efficiency, zero emission of air pollutant along its light weight and low temperature operation. However the major handicap of this technology is the high performance electrocatalyst that will overcome the slow nature of the cathodic ORR. Platinum is known to present the best catalytic activity for the oxygen reduction reaction (ORR) among all pure metals and when supported on a conductive carbon serves as state of the art electrocatalyst in low temperature fuel cell air cathodes (Gottesfeld et al., 1997). However, due to kinetic limitations of the oxygen reduction reaction the cathodic over potential losses amount to $0.3-0.4 \mathrm{~V}$ under typical polymer electrolyte fuel cell (PEMFC) operating conditions (Gottesfeld et al., 1997). In addition, Pt is expensive and the world's supply is limited. Therefore, the development of more active and less expensive oxygen reduction electrocatalysts than pure Pt has been the subject of extensive research for a number of decades and has favored the use of suitable Pt-alloys. 
Special Conference Edition, November, 2019

Among these, recent studies reported that Pt-Co alloys show enhanced catalytic activity compared to pure Pt for oxygen reduction (Santiago et al., 2007; Koh et al., 2007; Koh et al., 2007; Ferne'ndez et al., 2009; Do et al., 2007; Koh et al., 2007; Huang et al., 2006; Antolini et al., 2005; Slavcheva et al., 2005; Salgado et al., 2004; Salgado et al., 2004; Salgado et al., 2005; Hwang et al., 2007; Antolini et al., 2006). Generally, alloying of platinum using non-noble metals Pt-M ( $\mathrm{M}=$ transition metals such as $\mathrm{Co}$, $\mathrm{Ni}, \mathrm{Cu}, \mathrm{Fe}, \mathrm{Mn}$ e.t.c) has solve so many shortcoming of Fuel cell technology. Moorthi et al., (2017) fabricated one of the most durable Pt-alloy catalyst with $82 \%$ increase in mass activity after 30,000 potential cycle. Balamurugam et al., (2014) synthesized a Ptalloy catalyt with a shift of $0.85^{\circ}$ toward $2 \theta$ value. Tokako et al., (2012) prepared PtNi, PtCo and PtFe catalyst with enhanced electroreduction and they successfully formed an alloy of Pt with fcc structures. Changlin et al., (2015) prepared an octahedral $\mathrm{Pt}_{2} \mathrm{CuNi}$ alloy nanoparticle which shows that about $80 \%$ of the particles were in octahedral morphology and the XRD result reveals a remarkable shift in the positive $2 \theta$ value direction with fcc structiures. Dao-Jun Guo et al., (2014) prepared PtNi alloy nanoflowers with 4-7 nm diameter grains, fcc structure and corresponding diffraction angle (111), (200), (220), (311), the diffraction peaks were slightly shifted to the high $2 \theta$ values in the PtNi particles. Despite all the above observation still more work is needed to improve the catalytic activity of ternary-Pt based catalyst and to further insight into the catalyst structure. In the literature few works was done on ternary-Pt based alloy nano catalyst. Herein, we present a simple salvothermal method for preparation of ternary $\mathrm{PtM}_{2}\left(\mathrm{M}_{2}=\mathrm{Ni}\right.$ and $\left.\mathrm{Co}\right)$ based nano particle where time of synthesis aside $\mathrm{KI}$, that was considered as one of the factor contributing the nature and shape of the synthesized catalyst also play significant role. This was done by comparing the synthesized catalyst at $8 \mathrm{hrs}$. with another one at 16 hrs. that is PCN-8h and PCN$16 \mathrm{~h}$ respectively. The TEM Images indicated that multiple faces were formed which later agglomerate with time from 8 hrs. to $16 \mathrm{hrs}$. during synthesis.
MATERIALS AND METHODS

Platinum acetoacetate $\left(\mathrm{Pt}\left(\mathrm{CH}_{3} \mathrm{COO}\right)_{2}\right)$, Cobalt(II) acetate $\quad\left(\mathrm{Co}\left(\mathrm{CH}_{3} \mathrm{COO}\right)_{2}\right.$, Nickel acetate $\left(\mathrm{Ni}\left(\mathrm{CH}_{3} \mathrm{COO}\right)_{2}\right)$ and polyvinyl(2-pyrrolidone) (PVP, MW 55 000, in terms of its repeating units), were purchased from Aldrich Chemicals. perchloric acid $\left(\mathrm{HClO}_{4}\right)$ and solvents like NMP, Isopropyl Alcohol (IPA), ethanol and acetone were purchased from Wako Chemicals. Commercial $\mathrm{Pt} / \mathrm{C}$ and catalysts were purchased from Tanaka Kikinzoku Kogyo, Tokyo, Japan.

\section{Synthesis}

Synthesis of ternary Pt based nanoparticle under hydrothermal condition. $30 \mathrm{mg}$ of $\left(\mathrm{Pt}\left(\mathrm{CH}_{3} \mathrm{COO}\right)_{2}\right)$, was added to $14.97 \mathrm{mg}$ of $\left(\mathrm{Co}\left(\mathrm{CH}_{3} \mathrm{COO}\right)_{2}, 14.88 \mathrm{mg}\right.$ of $\left(\mathrm{Ni}\left(\mathrm{CH}_{3} \mathrm{COO}\right)_{2}\right), 160$ $\mathrm{mg}$ of PVP and $0.166 \mathrm{~g}$ of $\mathrm{KI}$ all these were dissolved in $15 \mathrm{ml}$ of DMF. The mixture was sonicated for 30 minutes to obtain a homogeneous mixture. A transparent solution was transferred into Teflon-lined stainless steel autoclave and kept at $150^{\circ} \mathrm{C}$ for 8 hrs. and 16 hrs. for different sample. Then carbon black was added to make $40 \%$ of the metal loaded sample. The mixture Sonicated for 30 minutes and kept under reflux condition at $160^{\circ} \mathrm{C}$ for 2 hours. The mixture was collected centrifuged, washed one time with acetone and three times with water, dried at $60{ }^{\circ} \mathrm{C}$ in drying oven and then grinded it into a fine powder, this followed by treating the nanoparticle catalyst in tubular furnace under Nitrogen atmosphere at $200^{\circ} \mathrm{C}$ for two hours to remove the capping agent.

\section{Characterization}

The resulting alloy compositions were confirmed with Scanning electron microscope SEM, energydispersive X-ray EDX studies to quantify the metal loading by 'Quanta 200 FEG FE-SEM'. Powder X-ray diffraction (XRD) was used to find out the structural analysis of Pt alloy nanoparticles and the measurement were performed on an X'part pro diffractometer, PAN analytical using CuK $\alpha$ line ( $\lambda=1.5406 \AA, 40 \mathrm{kV}$, $40 \mathrm{~mA}$ ) in the $2 \theta$ range of 20 to $100^{\circ}$ with a scan rate of $2^{0}$ per minute. FEI Tecnai T-20 electron microscope, operating at $200 \mathrm{kV}$ was used for TEM analysis. 
Special Conference Edition, November, 2019 RESULTS AND DISCUSSION

The composition of the $\mathrm{PtNiCo} / \mathrm{C}$ prepared electrocatalysts was determined by EDX analysis. Fig. 1 shows the typical EDX spectrum of the sample was found that the EDX atomic Pt:Ni:Co composition of that sample in various regions of the powders was 30:50:20, obtained for the sample prepared for $8 \mathrm{hrs}$.

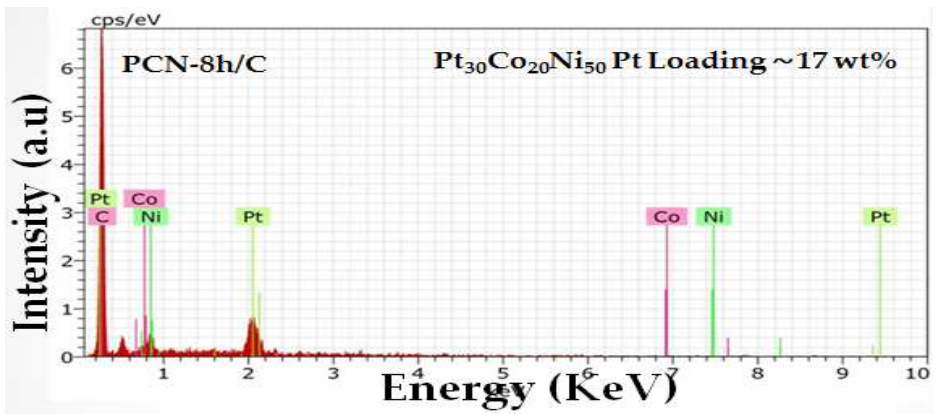

\begin{tabular}{|lcccc|}
\hline Catalyst & W\%Pt & W\%Ni & W\%Co & W\%C \\
\hline PCN-8h/C & $\mathbf{1 6 . 9 4}$ & 8.48 & 3.59 & 70.99 \\
PCN-16h/C & 24.41 & 8.07 & 3.59 & 64.41 \\
& & & & \\
\hline
\end{tabular}

Fig. 1. EDX spectrum of the PCN-8h alloy catalyst obtained at 8 hours
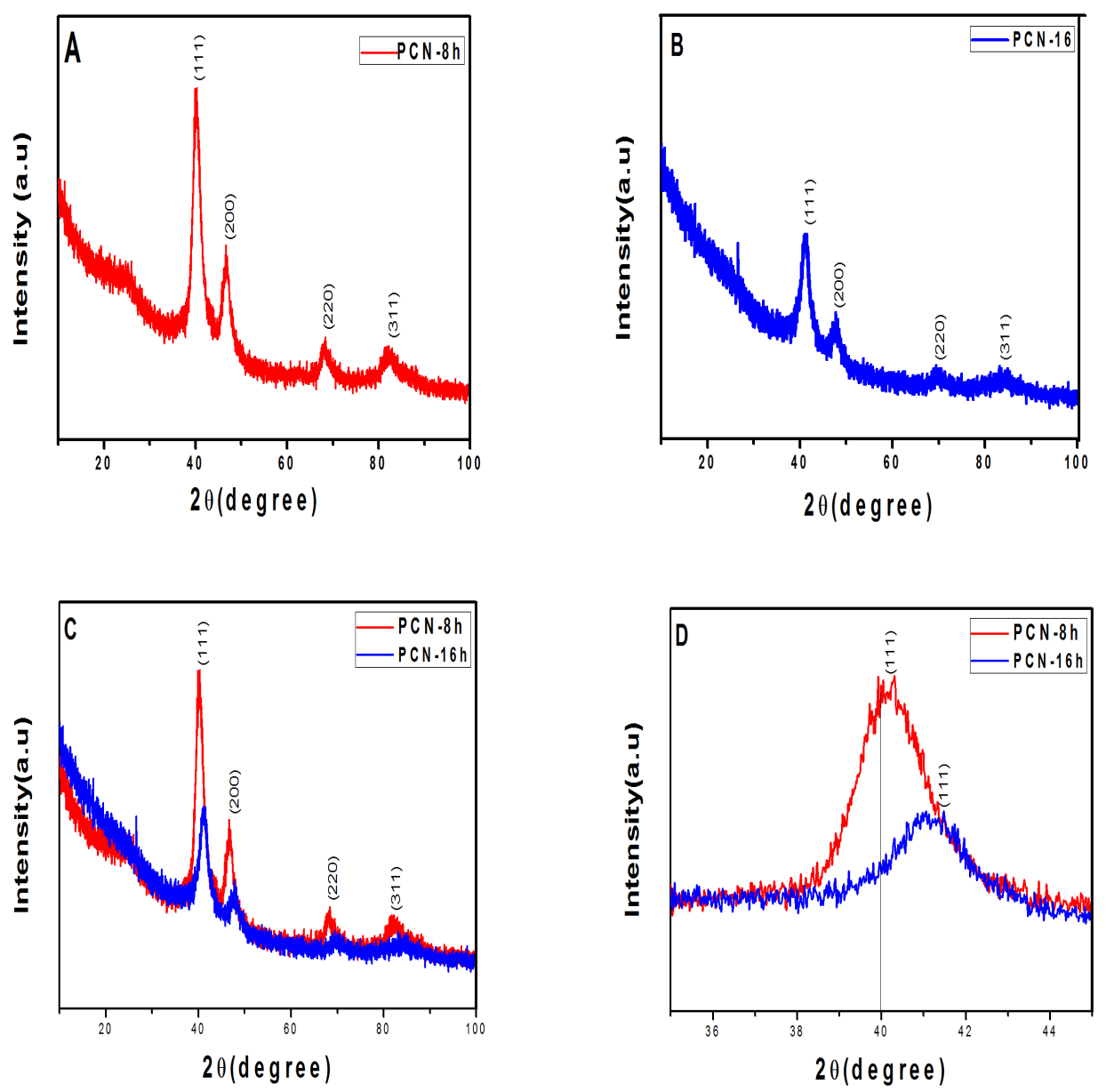

Fig. 2 (a) and (b) XRD pattern for PCN-8h/C and PCN-16h/C catalyst, (c) is the superimposed PCN$8 \mathrm{~h} / \mathrm{C}$ and $\mathrm{PCN}-16 \mathrm{~h} / \mathrm{C}$ showing more sharper and higher peak, (d) superimposed peak (111) plane 


\section{Special Conference Edition, November, 2019}

The presence of (111), (200), (220) and (311) plane shows the characteristic fcc structure of $\mathrm{Pt}$ with the introduction of $\mathrm{Ni}$ and $\mathrm{Co}$ into the fcc structure of Pt. the Pt reflux ions were shifted to higher $2 \theta$ values. fig $2 \mathrm{C}$ PCN-8hrs $0.25^{\circ}$ shift where PCN-16hrs $1.105^{\circ}$ shift. J.R.C salgado et al (2004). This clearly indicates the formation of an alloy. Even though there is no specific peak indicating the presence of $\mathrm{Ni}$ and Co. However the remarkable decrease in lattice parameters when compared to commercial Pt/C is enough/clear indication of the incooperation of $\mathrm{Ni}$ and $\mathrm{Co}$ into the fcc of the catalyst. It was observed that the peaks were more intense in $\mathrm{PCN} 8 \mathrm{~h} / \mathrm{C}$ more especially at (111) plane. This is attributed to the particle size. The average size of PCN-8h/C nanoparticle was estimated to be $4.3 \mathrm{~nm}$ using Sherrer's equation. (Warren, 1969) which more precisely when compared with the broader peak for PCN-16h/C at same (111) plane (Figure 2d.
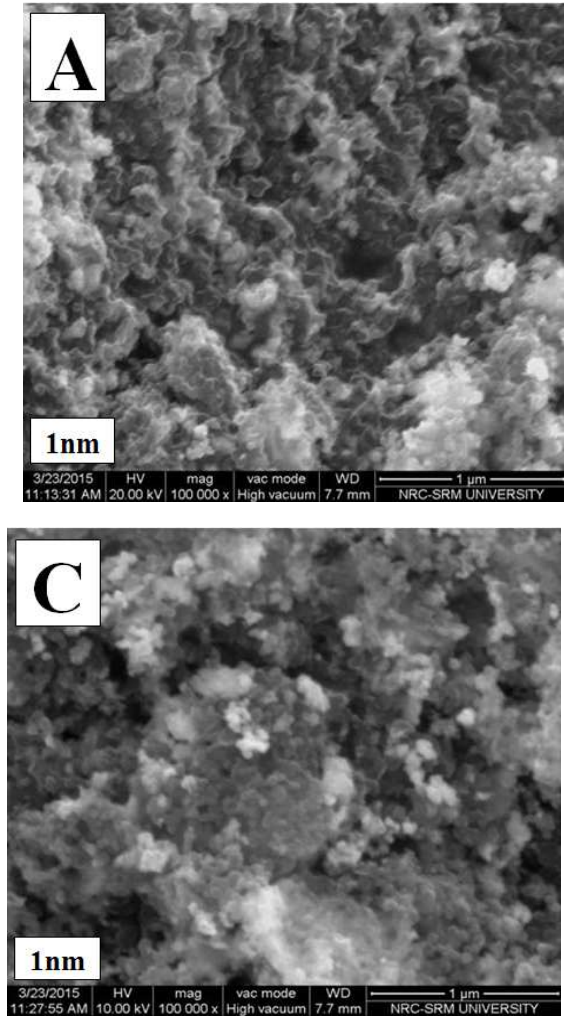
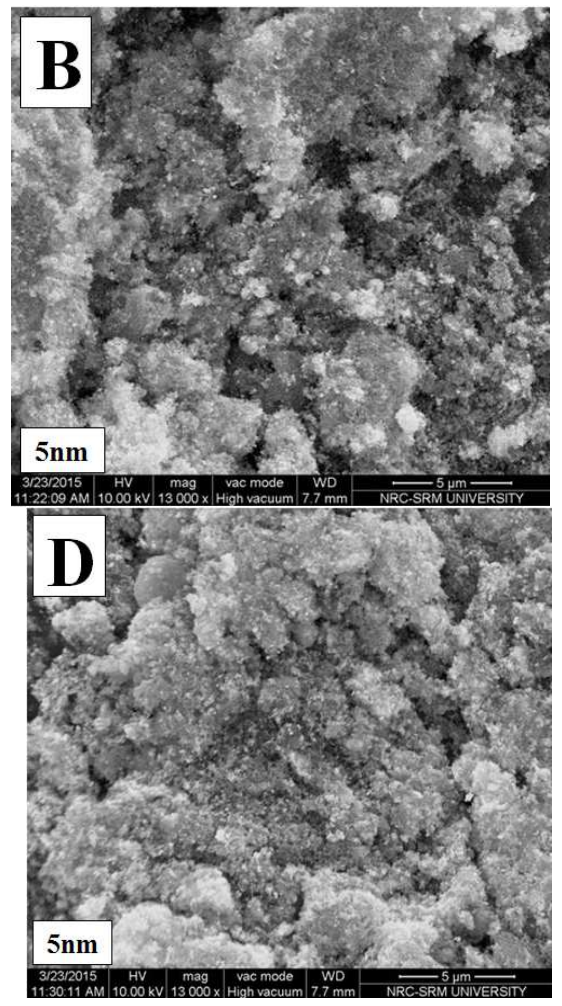

Fig 3. (a) and (b) low and high resolution of SEM images showing the surface morphology of PCN$8 \mathrm{~h} / \mathrm{C}$. (c) and (d) low and high resolution of SEM images showing the surface morphology of PCN$16 \mathrm{~h} / \mathrm{C}$

Fig. 3(a) and (b) clearly display the surface morphology of the prepared PCN-8h/C at different resolution, the appearance of the PCN/C were more clearly shown in high resolution of $5 \mathrm{~nm}$ in which the appearance of white spot indicated alloy formation while the black colour represent the carbon support. in fig 3. (c) and (d) is the PCN-16h/C at $1 \mathrm{~nm}$ and $5 \mathrm{~nm}$ respectively, the image in fig. 3 (d) indicate more of the alloy on the carbon support which nearly covered all the appearance of the carbon support this give a strong agreement with the TEM images that agglomerate as the time of synthesizing the alloy increases from 8 hrs. to 16 hrs. 

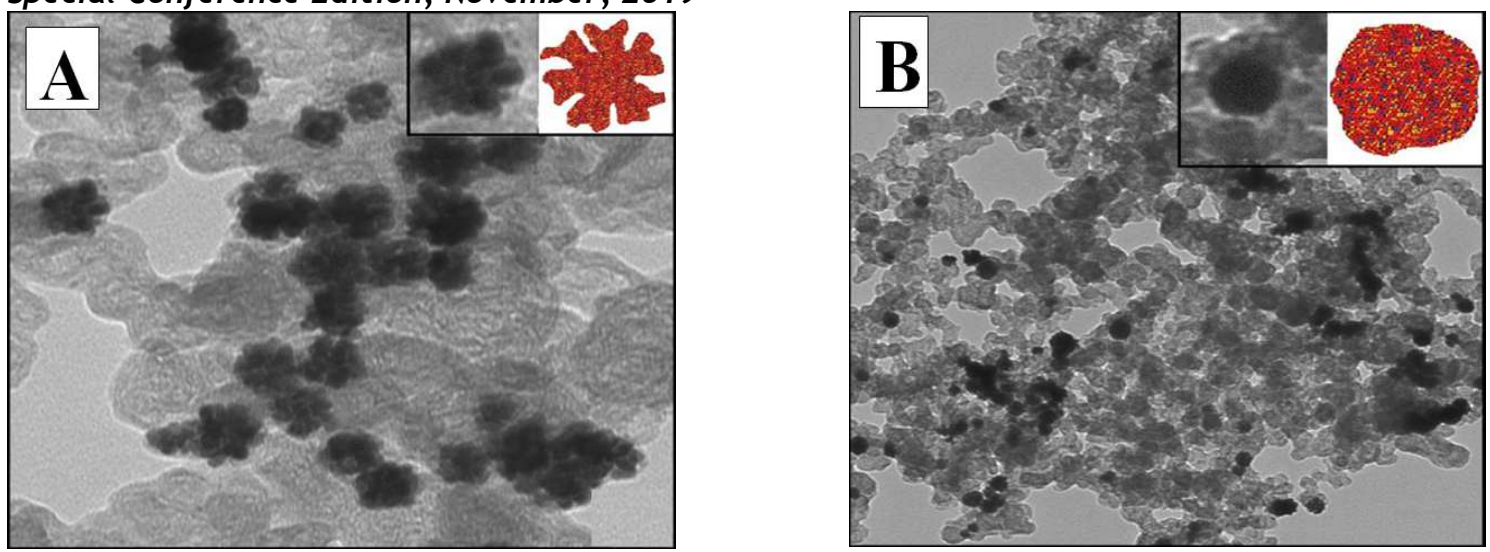

Fig.4. (a) and (b) TEM images for PCN-8h/C and PCN-16h respectively

Fig 4. (a) and (b) shows TEM images for PCN-8h/C and PCN-16h/C respectively but fig (a) shows multifaceted alloy which is an indication for more surface area for a reaction to take place but later the faces disappeared in fig 4 (b) this may be attributed to agglomeration. Despite the agglomeration observed for $\mathrm{PCN}-16 \mathrm{~h} / \mathrm{C}$ fig $4 \mathrm{~b}$ with disappearance of many faces when compare with $\mathrm{PCN}-8 \mathrm{~h} / \mathrm{C}$ fig $4 \mathrm{a}$ still the thickness of the particles decrease from 8 to $16 \mathrm{hrs}$., likewise the interplaner distance. And both of them were having smaller interplaner distance and particle thickness compare to commercial Pt/C. See table 1.
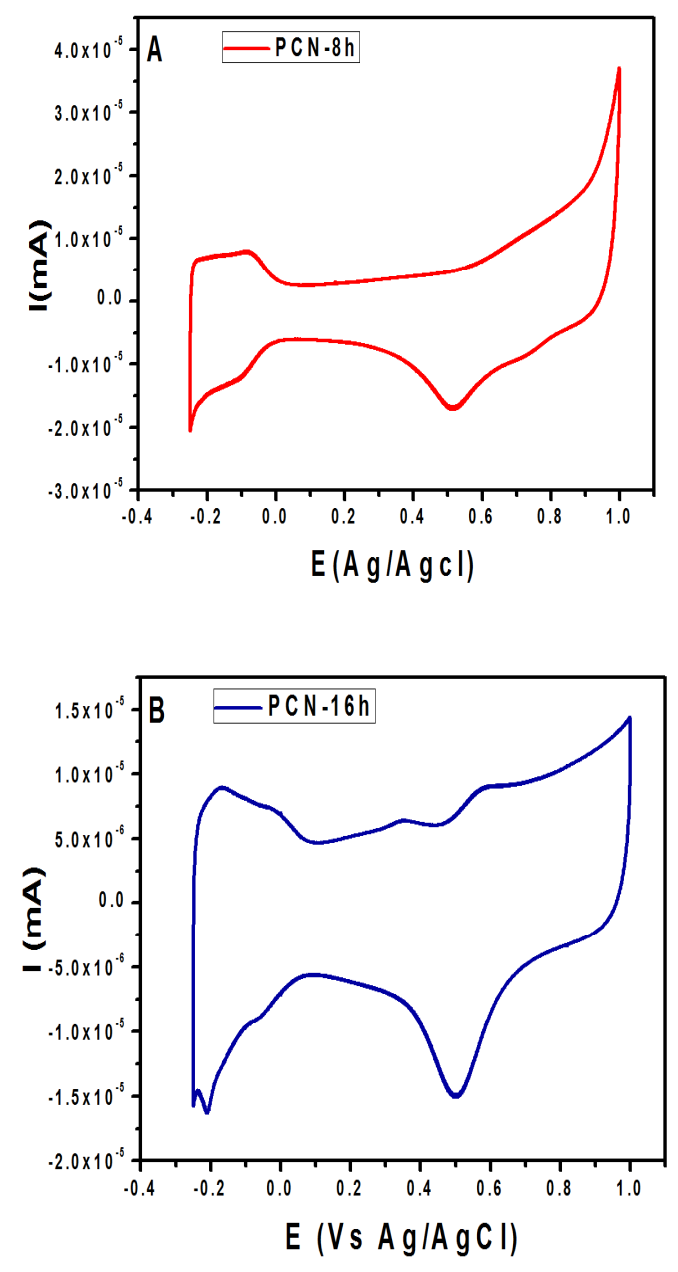


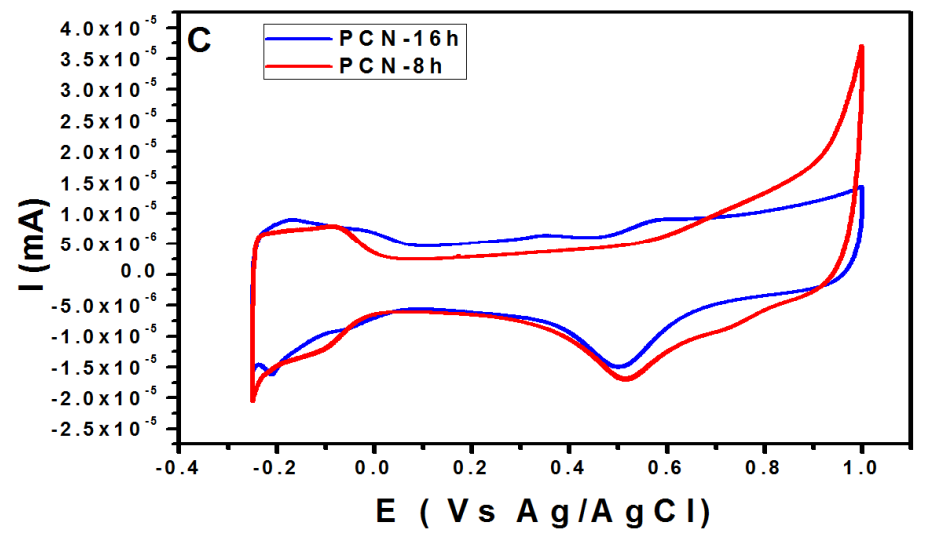

Fig. 5 (a) and (b) Cyclic Voltammetry curves for PCN-8h/C and PCN-16h/C respectively (c) superimposed Cyclic voltammetry for PCN-8h/C and PCN-16h/C

The performance as electrocatalyst for ORR was investigated by cyclic voltammetry (CV), rotating disc electrode (RDE) of $3 \mathrm{~mm}$ diameter glassy carbon all examinations were carried out in the two electrode system $\mathrm{Ag} / \mathrm{AgCl}$ as counter and reference electrodes in the presence of $\mathrm{N}_{2}-$ saturated, $0.1 \mathrm{M}$ perchloric acid solution at a scan rate of $20 \mathrm{mVs}^{-1}$ to confirm the areas of hydrogen absorption, hydrogen desorption and ORR. See fig. 5 (a) and (b) for PCN-8h/C and $\mathrm{PCN}-16 \mathrm{~h} / \mathrm{C}$ respectively. The superimposed CV was shown in fig. 5(c) for comparison. Further investigation on electrochemical characterization will be considered in future studies.

\section{CONCLUSION}

In summary, the multifaceted (PCN-8h/C and PCN-16/C) alloy was successfully synthesized using simple salvothermal method. XRD result reveals that; a shift towards high $2 \theta$ values of $0.25^{\circ}$ and $1.105^{\circ}$ for PCN-8h/C and PCN-16h/C respectively was observed, the particle thickness was found to be $\sim 4.30 \mathrm{~nm}$, the interplanner distance was also found to be $\sim 0.06 \mathrm{~nm}$ less than the commercial Pt/C, the lattice parameters was $\sim 0.01 \mathrm{~nm}$ less than the commercial Pt/C. Tem analysis indicated that the particle size was $\sim 20 \mathrm{~nm}$. In all the result it shows that, there is a strong agreement between the XRD, TEM, SEM and EDX.

\section{Acknowledgement}

The authors will like to thank the SRM research institute, Chemistry department SRM Institute of Science and technology, the research guide Dr. Bhalchandra A. Kakade.

Table 1: Structural characteristics of the PNC-8h/C, PCN-16h/C and Pt/C electrocatalyst

\begin{tabular}{cccc}
\hline Catalyst & $\begin{array}{c}\text { Lattice } \\
\text { Parameters }(\mathrm{nm})\end{array}$ & $\begin{array}{c}\text { Interplaner } \\
\text { Distance }(\mathrm{nm})\end{array}$ & $\begin{array}{c}\text { Particle } \\
\text { Thickness }(\mathrm{nm})\end{array}$ \\
\hline $\mathrm{Pt} / \mathrm{C}$ & 0.3901 & 0.281 & 4.40 \\
$\mathrm{PCN}-8 \mathrm{hrs} / \mathrm{C}$ & 0.381 & 0.22 & 4.26 \\
$\mathrm{PCN}-16 \mathrm{hrs} / \mathrm{C}$ & 0.364 & 0.21 & 4.21 \\
\hline
\end{tabular}

\section{REFERENCES}

Antolini E., Salgado J.R.C., Giz M.J., Gonzalez E.R., (2005) Effects of geometric and electronic factors on ORR activity of carbon supported Pt-Co electrocatalyst in PEM fuel cells. Int. J. Hydrogen Energy 301213.

Antolini E., Salgado J.R.C., Gonzalez E.R., (2006) The stability of Pt-M ( $M=$ first raow transition metal) alloy catalyst and its effect on the activity in low temperature fuel cell. J. Power Sources 160957.
Balamurugan Arumugam, Bhalchandra Kakade A., Takanori Tamaki, Masazumi Arao, Hideto Imaid and Takeo Yamaguchi (2014) Enhanced activity and durability for the electroreduction of oxygen at a chemically ordered intermetallic PtFeCo catalyst. RSC Adv., 4, 27510

Changlin Zhang, William Sandorf and Zhenmeng Peng (2015) Octahedral $\mathrm{Pt}_{2} \mathrm{CuNi}$ Uniform Alloy Nanoparticle Catalyst with High Activity and Promising Stability for 
Special Conference Edition, November, 2019

Oxygen Reduction Reaction. ASC Catalysis. 5, 2296

Dao-Jun Guo, Shu-Kun Cui, Dan Cheng, Peng Zhang, Li Jian, Can-Can Zhang (2014) One-pot Synthesis of PtNi alloy nanoflowers supported on Multi-walled carbon nanotubes with superior electrocatalytic activity for the oxygen reduction. J. of Power Source 255, 157

Do J.-S., Chen Y.-T., Lee M.-H., (2007) Effect of thermal annealing on the properties of $\mathrm{Co}$ rich core $-\mathrm{P}_{\text {trich }}$ shell $/ \mathrm{C}$ oxygen reduction electrocatalyst. J. Power Sources 172 623.

Ferna'ndez P.H., Rojas S., Oco' n P., Go'mez de la Fuente J.L., Terreros P., Peña M.A., Fierro J.L.G., (2007) Appl. Catal. B 7719.

Gottesfeld E., Zawodzinski T.A., Alkire R.C., Gerischer H., Kolb D.M., C.W.Tobias C.W., (1997) (Eds.), Advances in Electrochemical Science and Engineering, vol. 5, 1sted., Wiley VCH,Weinheim, p. 195.

Bushby L. (2006) Hydrogen Fuel Cells. Environmental Chemistry. Retrieved $12^{\text {th }}$ Sept.

2019. http://environmentalchemistry.com/yogi Lenvironmental/200608hydro genfuelcells.html.

Huang Q., Yang H., Tang Y., Lu T., Akins D.L., (2006) Carbon-Supported Pt-Co alloy nanoparticles for oxygen reduction reaction. Electrochem. Commun. 8 1220.

Hwang B.J., Kumar S.M.S., Chen C.-H., Monalisa, Cheng M.-Y., Liu D.-G., Lee J.F., (2007) An Investigation of StructureCatalytic Activity Relationship for PtCo/C Bimetallic Nanoparticles toward the Oxygen Reduction Reaction. J. Phys. Chem. C 11115267.

Koh S., Leisch J., Toney M.F., Strasser P., (2007) Structure-activity-stability Relationship of Pt-Co Alloy Electro catalyst in GasDiffusion Electrode Layers. J. Phys. Chem. C 1113744.

Koh S., Toney M.F., Strasser P., (2007) Activitystability relationships of ordered and disordered alloy phases of $\mathrm{Pt}_{3} \mathrm{C}_{0}$ electrocatalysts for the oxygen reduction reaction (ORR). Electrochim. Acta 52 2765.
Koh S., Yu C., Mani P., Srivastava R., Strasser P., (2007) Activity of ordered and disordered Pt-Co alloy phases for the electroreduction of oxygen in catalysts with multiple coexisting phases. $J$. Power Sources 17250.

Moorthi Lokanathan, Indrajit M. Patil, Alhasan Kabiru Usman, Anita Swami, Pravin Walke, M. Navaneethan and Bhalchandra Kakade (2017) Unusual enhancement in the electroreduction of oxygen by NiCoPt by surface turnability through potential cycling. RSC Adv., 7, 11777

Salgado J.R.C., Antolini E., Gonzalez E.R., (2004) $\mathrm{Pt}-\mathrm{Co} / \mathrm{C}$ Electrocatalyst for Oxygen Reduction in $\mathrm{H}_{2} / \mathrm{O}_{2}$ PEMFFCs Synthesized by Borohydride method $\mathrm{J}$. Electrochem. Soc. 151 A2143.

Salgado J.R.C., Antolini E., Gonzalez E.R., (2004) Structure and activity of Carbosupported Pt-Co Electrocatalyst for Oxygen Reduction. J. Phys. Chem. B 108 17767.

Salgado J.R.C., Antolini E., Gonzalez E.R., (2004) Preparation of $\mathrm{Pt}-\mathrm{Co} / \mathrm{C}$ electrocatalyst by reduction with borohydride in acid and alkaline media: the effect on the performance of the catalyst. J. Power Sources $13856-60$.

Santiago C.W., Varanda L.C., Villullas L.C., (2007) Carbon supported Pt-Co catalyst prepared by a modified polyol process as cathodes for PEM fuel cells. J. Phys. Chem. C 1113146.

Shafiee S., Topal E., (2009) When will fossil fuel reserves be diminished? Energ Policy 37 181-189.

Slavcheva E., Nikolova V., Petkova T., Lefterova E., Dragieva I., Vitanov T., Budevski E., (2005) Nanotechnological Bases for Advance Sensors. Electrochim. Acta 50 5444.

Thinnes B., (2012) Hydrocarb Process 91 1719.

Tokako Toda, Hiroshi Igarashi, Hiroyuki Uchida and Masahiro Watanabe, (1999) Enhancement of the Electroreduction of Oxygen on Pt Alloys with $\mathrm{Fe}, \mathrm{Ni}$ and $\mathrm{Co}$. J. of the Electrochemical Society 146, 3750

Warren B.E., (1969) X-ray Diffraction, AddisonWesley Pub. Co. (reprint) 